\title{
Comparison of two modern vaccines and previous influenza infection against challenge with an equine influenza virus from the Australian 2007 outbreak
}

\author{
Neil A. Bryant ${ }^{1 \dagger}$, Romain Paillot ${ }^{1}{ }^{1 *}$, Adam S. Rash ${ }^{1}$, Elizabeth Medcalf ${ }^{1}$, \\ Fernando Montesso ${ }^{1}$, Julie Ross ${ }^{1,2}$, James Watson ${ }^{3}$, Martyn JeGGO $^{3}$, \\ Nicola S. Lewis ${ }^{1,4}$, J. Richard Newton ${ }^{1}$, Debra M. Elton ${ }^{1}$ \\ ${ }^{1}$ Animal Health Trust, Centre for Preventive Medicine, Lanwades Park, Kentford, Newmarket, \\ CB8 7UU, United Kingdom \\ ${ }^{2}$ Present address: Department for Environment. Food and Rural Affairs, Nobel House, 17 Smith Square, \\ London, SW1P 3JR, United Kingdom \\ ${ }^{3}$ CSIRO Livestock Industries, Australian Animal Health Laboratory (AAHL), East Geelong VIC 3219, Australia \\ ${ }^{4}$ Department of Zoology, University of Cambridge, Downing Street, Cambridge, CB2 3EJ, United Kingdom
}

(Received 23 July 2009; accepted 28 October 2009)

\begin{abstract}
During 2007, large outbreaks of equine influenza (EI) caused by Florida sublineage Clade 1 viruses affected horse populations in Japan and Australia. The likely protection that would be provided by two modern vaccines commercially available in the European Union (an ISCOM-based and a canarypox-based vaccine) at the time of the outbreaks was determined. Vaccinated ponies were challenged with a representative outbreak isolate (A/eq/Sydney/2888-8/07) and levels of protection were compared. A group of ponies infected 18 months previously with a phylogenetically-related isolate from 2003 (A/eq/South Africa/4/03) was also challenged with the 2007 outbreak virus. After experimental infection with A/eq/Sydney/2888-8/07, unvaccinated control ponies all showed clinical signs of infection together with virus shedding. Protection achieved by both vaccination or long-term immunity induced by previous exposure to equine influenza virus (EIV) was characterised by minor signs of disease and reduced virus shedding when compared with unvaccinated control ponies. The three different methods of virus titration in embryonated hens' eggs, EIV NP-ELISA and quantitative RT-PCR were used to monitor EIV shedding and results were compared. Though the majority of previously infected ponies had low antibody levels at the time of challenge, they demonstrated good clinical protection and limited virus shedding. In summary, we demonstrate that vaccination with current EIV vaccines would partially protect against infection with A/eq/Sydney/2888-8/07-like strains and would help to limit the spread of disease in our vaccinated horse population.
\end{abstract}

equine influenza / vaccine / protection / outbreak / antibody

\section{INTRODUCTION}

Equine influenza viruses (EIV) are major respiratory pathogens of horses, causing high morbidity and occasional mortality. Equine

\footnotetext{
† These authors contributed equally to this work.

* Corresponding author: romain.paillot@aht.org.uk
}

influenza (EI) is a highly contagious disease and is contracted by inhalation of infectious virus aerosols. EI is not only an important welfare issue but can have a profound economic impact on the equine industry with major epidemics disrupting horse racing and breeding.

In horses, two different subtypes have been isolated, H7N7 and H3N8. The H7N7 subtype 
was first recognised in Eastern Europe in 1956, in an outbreak where the prototype strain A/eq/ Prague/56 was isolated [31]. The H7N7 viruses have not been isolated from horses for over 25 years [33].

Equine influenza H3N8 viruses were first isolated in North America in 1963 [32] and continue to be isolated to this day [2, 17]. Phylogenetic analyses of these isolates identified a divergence in the evolution of the H3N8 subtype in the late 1980s giving rise to the Eurasian and American lineages, which have continued to co-circulate [2, 5]. The American lineage has subsequently diverged again into the Kentucky and Florida sublineages [16], the latter of which has since divided into two separate clades, designated clade 1 and $2^{1}$ [2]. The majority of the recently isolated viruses in North America and the UK belong to the Florida sublineage clades 1 and 2, respectively [2].

Vaccines for EIV have been available since the 1960s, but EIV continues to cause episodic outbreaks of disease worldwide in both vaccinated and unvaccinated horses. Historically vaccines against EIV have consisted of inactivated whole virus preparations mixed with different adjuvants $[15,30]$. Vaccine strains used have also varied worldwide. Protection induced by this type of vaccine is primarily mediated by antibodies against the haemagglutinin surface glycoprotein (HA). Protection correlates with serum antibody levels as measured by single radial haemolysis (SRH) [20, 21, 34]. Previous work using a Welsh Mountain pony challenge model showed that protection from experimental infection with EIV correlated with the antigenic relatedness of the vaccine to the challenge virus strain $[6,37]$.

Natural infection with EIV confers a longterm immunity to re-infection with a homologous strain even in the absence of antibodies at the time of re-infection [11]. In order to mimic more closely the protective immunity induced by EIV, a

\footnotetext{
${ }^{1}$ OIE, Conclusion and recommendations from the Expert Surveillance Panel on Equine Influenza Vaccines, 2008, pp. 42-45. http://www.oie.int/eng/ publicat/BULLETIN\%20PDF/Bull\%202008-2-ENG. pdf [consulted 21 October 2008].
}

new generation of vaccines has been designed to stimulate both antibody and cell-mediated immunity [26]. In addition to improvements in vaccine technology, efforts have been made by a number of laboratories to monitor the antigenicity of circulating EIV strains in order to provide data for appropriate vaccine strain selection. Currently there is recommendation for a Florida sublineage isolate (A/eq/South Africa/4/03-like) or equivalent ${ }^{1}$. Modern vaccine technologies are now being employed for EIV vaccination including the use of Immuno-stimulating complexes (ISCOM) and matrices [4, 12, 13, 23, $26,29]$ and recombinant poxvirus vectors [10, 19]. At the time of this study, the ProteqFlu ${ }^{\mathrm{TM}}$ vaccine (Merial Animal Health Ltd, Harlow, UK) contained two recombinant canarypox viruses expressing the HA of $\mathrm{A} / \mathrm{eq} / \mathrm{Kentucky} / 94$ (American lineage, H3N8) and A/eq/Newmarket/ 2/93 (Eurasian lineage, H3N8). This vaccine was shown to significantly reduce clinical signs and to prevent virus shedding in ponies challenged 2 weeks post V2 with A/eq/Newmarket/ $5 / 03[10,27]$. $\mathrm{A} /$ eq/Newmarket/5/03 is a member of the Florida sublineage clade 2 viruses commonly found in the UK and was responsible for the large outbreak seen in vaccinated horses in Newmarket in 2003 [25]. The authors note that since this study was conducted Merial has updated its ProteqFlu ${ }^{\mathrm{TM}}$ vaccine to now include the virus strain $\mathrm{A} / \mathrm{eq} / \mathrm{Ohio} / 03$ (American lineage, H3N8), as recommended by the OIE in $2006^{2}$.

Equip $^{\text {TM }} \mathrm{F}$ (Schering Plough Animal Health, Hertfordshire, UK) was an ISCOM-based vaccine containing the strains A/eq/Newmarket/77 (H7N7), A/eq/Kentucky/98 (American lineage, H3N8) and A/eq/Borlange/91 (Eurasian lineage, H3N8). It was shown to significantly reduce clinical signs and to prevent virus shedding in ponies after experimental infection with $\mathrm{A} / \mathrm{eq} /$ South Africa/4/03 2 weeks post second vaccination (V2) [8, 29]. A/eq/South Africa/4/03

\footnotetext{
${ }^{2}$ OIE, Conclusion and recommendations from the Expert Surveillance Panel on Equine Influenza Vaccines, 2006, pp. 35-36. http://www.oie.int/eng/ publicat/BULLETIN\%20PDF/Bull\%202006-2-ENG. pdf [consulted 12 November 2007].
} 
was isolated from the large 2003 outbreak in naïve horses in South Africa and is representative of the Florida sublineage clade 1 viruses. Both vaccines were able to induce EIV-specific IFN- $\gamma$ synthesis by peripheral blood lymphocytes, suggesting the vaccines stimulated cellmediated immunity by directly activating Th1 cells [27, 29].

In mid-August 2007 an outbreak of EIV was detected in a partially vaccinated horse population in Japan [14, 36]. Later that month EIV was detected in a naïve population in Australia ${ }^{3}$. EIV infection spread rapidly in both countries, eventually infecting over 75000 animals in Australia [9]. Molecular characterisation of the representative virus A/eq/Sydney/2888-8/07 has classified it as a member of the Florida sublineage clade 1 viruses, typical of viruses recently isolated in North America. Of particular concern to the racing industry in the UK was the apparent vaccine breakdown observed in Japan. The vaccine used was a whole inactivated EIV vaccine containing the strains $\mathrm{A} / \mathrm{eq} / \mathrm{La}$ Plata/93 (American lineage, H3N8), A/eq/Avesta/93 (Eurasian lineage, $\mathrm{H} 3 \mathrm{~N} 8$ ) and $\mathrm{A} / \mathrm{eq} / \mathrm{Newmarket} /$ 77 (H7N7) [36]. These strains are phylogenetically similar to the strains used in the vaccines available in the EU at the time. This raised the concern that vaccines available at the time may have also been vulnerable to breakdown when challenged with this or a related virus, as seen in 2003 with the emergence of A/eq/Newmarket/5/03 that infected both vaccinated and nonvaccinated equids in Europe [1,25].

Here we determine the level of protection provided by two modern vaccines, namely Equip $^{\mathrm{TM}} \mathrm{F}$ and ProteqFlu ${ }^{\mathrm{TM}}$, against experimental infection with a virus isolated from the Australian EIV outbreak in 2007. To this end Welsh Mountain ponies were challenged 2 weeks post V2 to reflect a situation in which animals would be vaccinated during an outbreak. Virus shedding, a key element to control in order to halt viral spread, was monitored using three different methods. The long-term immunity of

\footnotetext{
${ }^{3}$ Callinan I., Equine Influenza: The August 2007 outbreak in Australia, Commonwealth of Australia, 2008, www.equineinfluenzainquiry.gov.au.
}

ponies experimentally infected with the phylogenetically-related isolate $\mathrm{A} / \mathrm{eq} / \mathrm{South}$ Africa/4/03 was also tested.

\section{MATERIALS AND METHODS}

\subsection{Vaccine}

Two vaccines commercially available in the EU were used in the study; ProteqFlu ${ }^{\mathrm{TM}}$ (Merial Animal Health Ltd, batch number L212428) containing two recombinant canarypox viruses expressing the HA of $\mathrm{A} / \mathrm{eq} /$ Newmarket $/ 2 / 93$ and $\mathrm{A} / \mathrm{eq} /$ Kentucky/94 and an ISCOM-based vaccine, Equip ${ }^{\mathrm{TM}} \mathrm{F}$ (Schering Plough Animal Health, batch number A582A2) containing inactivated antigens from $\mathrm{A} / \mathrm{eq} / \mathrm{Newmarket} /$ 77, A/eq/Borlänge/91 and A/eq/Kentucky/98.

\subsection{Animals}

Nineteen Welsh Mountain ponies aged between 1-2 years were used on the study. They were kept in accordance with the animal care guidelines of the Animal Health Trust Ethical Review Committee and under a home office project licence. Ponies were identified by a microchip in the neck. The sera of the 15 unvaccinated animals were tested by haemagglutination inhibition (HI) assay [5] and were seronegative for EIV at the start of the study. The four ponies previously infected with $\mathrm{A} / \mathrm{eq} / \mathrm{South}$ Africa/4/03 (18 months prior to the current study) were seronegative prior to the initial challenge. During the vaccination phase, ponies were kept together at grass. During the challenge phase, ponies were housed in the Allen Centre for Vaccine Studies (ACVS), an ACDP (Advisory Committee on Dangerous Pathogens) category 3 containment facility.

\subsection{Challenge virus}

Equine influenza virus strain $\mathrm{A} / \mathrm{eq} / \mathrm{Sydney} /$ 2888-8/07 (Passage 4 in eggs) was passaged once in ovo to provide the challenge stock (Passage 5). EIV suspensions were titrated in embryonated hen's eggs using the method of Reed and Muench and expressed in $50 \%$ egg infectious doses per $\mathrm{mL}$ $\left(\mathrm{EID}_{50} / \mathrm{mL}\right)$.

\subsection{Vaccination protocol}

The 15 naïve ponies were randomly assigned to three groups of 5. Control ponies (Group 1) were 
not vaccinated. Five ponies (Group 2) received two doses of ProteqFlu ${ }^{\mathrm{TM}}$ and five ponies (Group 3) received two doses of Equip $^{\mathrm{TM}} \mathrm{F}$, both 5 weeks apart and by deep intramuscular injection into the neck. Group 4 contained 4 ponies experimentally infected with $\mathrm{A} / \mathrm{eq} /$ South Africa/4/03 18 months prior to the current study. These ponies were not vaccinated. All ponies were clinically examined daily from the day before and up to 3 days after each vaccination step. Rectal temperatures between $37.0^{\circ} \mathrm{C}$ and $38.8^{\circ} \mathrm{C}$ were considered within the normal range.

\subsection{Challenge protocol}

Ponies were challenged on day 49, 2 weeks post V2. Each group of ponies was exposed to an aerosol of approximately $20 \mathrm{~mL}$ of allantoic fluid diluted in PBS containing $10^{7.7} \mathrm{EID}_{50}$ of $\mathrm{A} / \mathrm{eq} /$ Sydney/2888-8/07 virus (after back titration in eggs) using a model ULTRA 2000 nebuliser (DeVilbiss, Somerset, PA, USA). Air handling within the ACDP category 3 containment facility was reduced for the duration of the challenge protocol $(60 \mathrm{~min})$. Each pony was examined clinically from 1 day before challenge through to 14 days post-challenge, then released to pasture following full recovery. Clinical signs of disease (nasal discharge, cough, inappetance, lethargy and dyspnoea) were recorded for each pony on each day resulting in an overall clinical score per day as described previously [10]. Ponies exhibiting signs consistent with the development of a secondary bacterial infection were treated with trimethoprim potentiated sulphonamide antibiotic (Trimediazine; Fort Dodge Animal Health, Southampton, UK) according to the data sheet recommended dose.

\subsection{Serology}

Jugular venous blood samples were collected from each pony on days $-7,0$ (immediately before V1), 14, 28, 35 (immediately before V2), 42, 49 (immediately before challenge), 56, 63 and 77 . Serum was tested for the presence of antibody to EIV challenge strains (A/eq/South Africa/4/03 and $\mathrm{A} / \mathrm{eq} / \mathrm{Sydney} / 2888-8 / 07)$ and to representatives of vaccine strains (A/eq/Newmarket/1/93 and A/eq/ Newmarket/2/93) using the SRH assay [35]. SRH antibody levels were expressed as the area of the zone of haemolysis in $\mathrm{mm}^{2}$ and were measured in duplicate. Seroconversion was defined as an increase in the haemolysis zone of $25 \mathrm{~mm}^{2}$ or $50 \%$ between pre- and post-infection sera.

\subsection{Virus detection}

Nasopharyngeal swabs were taken from each pony on the day of $\mathrm{V} 1$, the day before challenge, the day after challenge and for each subsequent day until 2 weeks post-challenge [24]. Swabs were placed in sterile tubes containing $5 \mathrm{~mL}$ virus transport medium (VTM) consisting of PBS, $200 \mathrm{U} / \mathrm{mL}$ streptomycin, $150 \mathrm{U}$ penicillin, $5 \mathrm{mg} / \mathrm{mL}$ fungizone (Gibco) and $600 \mathrm{mg} / \mathrm{mL}$ tryptone phosphate broth. All subsequent work was carried out within a class 2 microbiological safety cabinet (SCR-327, Labcaire Systems Ltd, Avon, UK) using sterile instruments for each swab. Swabs were wrung out and the resultant extract was stored at $-70{ }^{\circ} \mathrm{C}$. Suspensions were diluted 10 -fold from neat to $10^{-4}$ and $100 \mu \mathrm{L}$ from each dilution was inoculated into the allantoic cavities of 10 day old embryonated hens' eggs (two eggs per dilution). Eggs were incubated at $34{ }^{\circ} \mathrm{C}$ and harvested 3 days post-infection. Virus was detected by HA assay using $1 \%$ chicken erythrocytes in PBS and viral titre was expressed as $\mathrm{EID}_{50} / \mathrm{mL}$ swab extract. Extracts were also tested for the presence of virus using the NP-ELISA as previously described [3]. The cut-off point for positive samples for the NPELISA was set at twofold background. Quantitative RT-PCR reactions were set up within HEPA filtered laminar flow hoods (PCR6, Labcaire Systems Ltd) and was carried out using a Techne Quantica ${ }^{\circledR}$. Viral RNA was isolated from $140 \mu \mathrm{L}$ nasopharyngeal swab extract using the QIAampViral RNA mini kit (Qiagen) according to the manufacturer's instructions and eluted in $50 \mu \mathrm{L}$. RNA standards were included alongside the nasopharyngeal swab extracts. Primers and a fluorescent probe incorporating 8 locked nucleic acids (Proligo) targeting segment 5 (NP) were designed using the Beacon Designer 6.0 program (Biosoft) and were as follows: NP forward primer 5'-TTCTGGAGAGGTGAAAATGG-3', NP reverse primer 5'-CATAAACACAGGCAGGTAGG-3'，NP probe $5^{\prime}$-(6FAM)-ACCAGAATTGCTTATGAAAG AATG-(BHQ1)-3'. The quantitative RT-PCR reaction was conducted using a Quantace 1 step kit (Cat no. QT 205-02) consisting of 1× SensiMix one step buffer, $250 \mathrm{nM}$ forward and reverse primer, $165 \mathrm{nM}$ probe, $3.8 \mathrm{mM} \mathrm{MgCl}_{2}$, $4 \mathrm{U}$ RNase Inhibitor, and $2 \mu \mathrm{L}$ of extracted RNA solution per reaction. The program used consisted of an RT step of $42{ }^{\circ} \mathrm{C}$ for $30 \mathrm{~min}$, a hot start activation step of $95^{\circ} \mathrm{C}$ for $10 \mathrm{~min}$ followed by 45 cycles of $95^{\circ} \mathrm{C}$ for $15 \mathrm{~s}, 60^{\circ} \mathrm{C}$ for $1 \mathrm{~min}$ and $72{ }^{\circ} \mathrm{C}$ for $30 \mathrm{~s}$. Each sample was tested in duplicate wells. Data was analysed using the Techne Quansoft program version 1.1.21. A cut-off value of 100 copies from $5.6 \mu \mathrm{L}$ 
of swab extract was used for determining positive samples.

\subsection{Statistical analysis}

This study tested the null hypotheses that the severity of clinical signs and amount of viral shedding were not different between groups of vaccinated and non-vaccinated ponies. Statistically significant differences in the different parameters measured (serological responses, clinical scores, and total and peak levels of virus shedding) between groups of vaccinated and non-vaccinated animals were evaluated using either the parametric one-way analysis of variance (ANOVA) or non-parametric Kruskal Wallis test, depending on whether the data were normally distributed and had equal variances. Stata 9 software (StataCorp, College Station, Texas, USA) was used for analyses and the level of statistical significance was set at $p \leq 0.05$.

\section{RESULTS}

\subsection{Antibody responses to vaccination or previous infection}

Antibody levels were tested by SRH assay against 4 different antigens: 2 representatives of vaccine strains (i.e. A/eq/Newmarket/1/93 and $\mathrm{A} / \mathrm{eq} / \mathrm{Newmarket} / 2 / 93$ ) and 2 challenge strains (A/eq/South Africa/4/03 and A/eq/ Sydney/07). None of the 15 naïve ponies had detectable EIV-specific HI antibodies at the beginning of the study (data not shown). The mean serum SRH antibody responses following V1, V2 and challenge infection with A/eq/ Sydney/2888-8/07 for each of the four groups are reported in Table I. All 5 control ponies (Group I) had undetectable EIV-specific SRH antibody levels throughout the vaccination phase. They all seroconverted to EIV when measured by SRH assay against A/eq/South Africa/4/03, A/eq/Sydney/2888-8/07, $\mathrm{A} /$ eq/Newmarket/2/93 and A/eq/Newmarket/1/ 93 after experimental infection (Tab. I). After 2 weeks post V1, the vaccinated ponies in Group 2 (ProteqFlu ${ }^{\mathrm{TM}}$ ) had mean antibody levels of between 75 and $142 \mathrm{~mm}^{2}$ and ponies in Group 3 (Equip $^{\mathrm{TM}} \mathrm{F}$ ) had mean zone areas of between 17 and $145 \mathrm{~mm}^{2}$ when using A/eq/ South Africa/4/03 as the antigen. At 2 weeks post V2, on the day of challenge, antibody levels were measured against the vaccine components or related viruses antigenically as close as possible to the vaccine strains [2]. Antibody levels were between $118 \mathrm{~mm}^{2}$ and $167 \mathrm{~mm}^{2}$ (mean value of $146 \mathrm{~mm}^{2}$ ) for Group 2 (ProteqFlu ${ }^{\mathrm{TM}}$ ) and between $93 \mathrm{~mm}^{2}$ and $209 \mathrm{~mm}^{2}$ (mean value of $133 \mathrm{~mm}^{2}$ ) for Group 3 (Equip $^{\text {TM }} \mathrm{F}$ ) when tested against A/eq/Sydney/ $2888-8 / 07$, the challenge strain. SRH antibody levels of between 116 and $186 \mathrm{~mm}^{2}$ (mean value of $146.6 \mathrm{~mm}^{2}$ ) in Group 2 (ProteqFlu ${ }^{\mathrm{TM}}$ ) and between 97 and $209 \mathrm{~mm}^{2}$ (mean value of $154 \mathrm{~mm}^{2}$ ) zone areas in Group 3 (Equip $^{\mathrm{TM}} \mathrm{F}$ ) using A/eq/South Africa/4/03 as the antigen that is genetically closely related to A/eq/Sydney/ $2888-8 / 07$. Similar antibody levels of between $132 \mathrm{~mm}^{2}$ and $177 \mathrm{~mm}^{2}$ (mean value of $150 \mathrm{~mm}^{2}$ ) for Group 2 (ProteqFlu ${ }^{\mathrm{TM}}$ ) and between $81 \mathrm{~mm}^{2}$ and $189 \mathrm{~mm}^{2}$ (mean value of $128 \mathrm{~mm}^{2}$ ) for Group 3 (Equip $^{\mathrm{TM}} \mathrm{F}$ ) were obtained when using A/eq/Newmarket/1/93 as the antigen in the SRH assay that was closely related to a component of ProteqFlu ${ }^{\mathrm{TM}}$ and closely related to $\mathrm{A} / \mathrm{eq} /$ Borlange/91 in Equip F. At 2 weeks post-challenge, the 5 ponies in Group 2 seroconverted after challenge infection when tested by SRH against A/eq/Sydney/ 2888-8/07 and A/eq/Newmarket/2/93 but only 3 seroconverted when tested against $\mathrm{A} / \mathrm{eq} /$ South Africa/4/03 and A/eq/Newmarket/1/93. Against A/eq/South Africa/4/03 these three ponies had the lowest mean SRH antibody levels before challenge of between 116 and $170 \mathrm{~mm}^{2}$, while the resistant ponies had levels of 174 and $186 \mathrm{~mm}^{2}$. At 2 weeks postchallenge, 4 of the 5 ponies in Group 3 seroconverted when comparing pre- and post-challenge sera against A/eq/South Africa/4/03 and A/eq/ Sydney/2888-8/07 antigens in the SRH assay. These four ponies had the lowest mean prechallenge SRH antibody levels of between 97 and $167 \mathrm{~mm}^{2}$ while the resistant pony (\#3689) had an SRH antibody level of $209 \mathrm{~mm}^{2}$ against both antigens (Tab. I). When tested against $\mathrm{A} / \mathrm{eq} /$ South Africa/4/03 and A/eq/Newmarket/ $1 / 93,4$ and 2 of the ponies seroconverted respectively. SRH assays on sera from the previously infected ponies detected the presence of antibodies with a mean clearance zone pre-challenge 
Table I. Humoral response to vaccination as measured by the single radial haemolysis (SRH) assay ( $\mathrm{mm}^{2}$ ) with A/eq/South Africa/4/03 (SA/4/03), A/eq/ Newmarket/2/93 (N/2/93), A/eq/Newmarket/1/93 (N/1/93) and A/eq/Sydney/2888-8/07 (SY/07) used as antigens. Post-infection seroconversions are indicated in italic text and were taken as an increase in the haemolysis zone of $25 \mathrm{~mm}^{2}$ or $50 \%$ between pre- and post-infection sera.

\begin{tabular}{|c|c|c|c|c|c|c|c|c|c|c|c|}
\hline $\begin{array}{l}\text { Time point } \\
\text { SRH antigen }\end{array}$ & $\begin{array}{c}\mathrm{V} 1 \\
\mathrm{SA} / 4 / 03\end{array}$ & $\begin{array}{l}\mathrm{V} 1+14 \mathrm{~d} \\
\mathrm{SA} / 4 / 03\end{array}$ & $\begin{array}{l}\mathrm{V} 1+28 \mathrm{~d} \\
\mathrm{SA} / 4 / 03\end{array}$ & $\begin{array}{l}\mathrm{V} 2+14 \mathrm{~d} \\
\mathrm{SA} / 4 / 03\end{array}$ & $\begin{array}{c}\mathrm{V} 2+14 \mathrm{~d} \\
\mathrm{~N} / 2 / 93\end{array}$ & $\begin{array}{c}\mathrm{V} 2+14 \mathrm{~d} \\
\mathrm{SY} / 07\end{array}$ & $\begin{array}{c}\mathrm{V} 2+14 \mathrm{~d} \\
\mathrm{~N} / 1 / 93\end{array}$ & $\begin{array}{l}\mathrm{C}+14 \mathrm{~d} \\
\mathrm{SA} / 4 / 03\end{array}$ & $\begin{array}{c}C+14 d \\
N / 2 / 93\end{array}$ & $\begin{array}{c}C+14 d \\
S Y / 07\end{array}$ & $\begin{array}{r}C+14 c \\
N / 1 / 93\end{array}$ \\
\hline \multicolumn{12}{|c|}{ Group 1 - Controls } \\
\hline \#1992 & 0 & 0 & 0 & 0 & 0 & 0 & 0 & 138.1 & 107.9 & 174.3 & 115.6 \\
\hline \#2234 & 0 & 0 & 0 & 0 & 0 & 0 & 0 & 204.1 & 188.9 & 236.1 & 138.1 \\
\hline \#3241 & 0 & 0 & 0 & 0 & 0 & 0 & 0 & 142.4 & 98.6 & 169.6 & 84.5 \\
\hline \#3791 & 0 & 0 & 0 & 0 & 0 & 0 & 0 & 179.1 & 184 & 244.5 & 184 \\
\hline$\# 5654$ & 0 & 0 & 0 & 0 & 0 & 0 & 0 & 142.4 & 133.9 & 164.9 & 123.6 \\
\hline \multicolumn{12}{|c|}{ Group 2 - ProteqFlu } \\
\hline \#2217 & 0 & 115.6 & 136 & 115.6 & 59.4 & 117.6 & 136 & 225.1 & 188.9 & 214.5 & 174.3 \\
\hline \#2666 & 0 & 74.6 & 109.8 & 169.6 & 107.9 & 144.6 & 151.6 & 230.6 & 204.1 & 219.8 & 176.7 \\
\hline \#3409 & 0 & 96.7 & 125.6 & 123.6 & 62.3 & 127.6 & 131.8 & 253 & 236.1 & 303.8 & 198.9 \\
\hline \#3712 & 0 & 142.4 & 131.8 & 174.3 & 106 & 167.2 & 176.7 & 146.8 & 162.6 & 193.9 & 160.3 \\
\hline \#5728 & 0 & 82.8 & 109.8 & 186.4 & 107.9 & 167.2 & 155.7 & 179.1 & 164.9 & 196.4 & 131.8 \\
\hline \multicolumn{12}{|c|}{ Group 3 - EquipF } \\
\hline \#3013 & 0 & 55.1 & 59.4 & 96.7 & 47 & 93.2 & 81.1 & 179.1 & 184 & 206.6 & 107.9 \\
\hline \#3170 & 0 & 16.7 & 34.8 & 102.2 & 65.3 & 111.7 & 96.7 & 193.9 & 184 & 209.2 & 162.6 \\
\hline \#3689 & 0 & 144.6 & 102.2 & 209.2 & 136 & 209.2 & 188.7 & 160.3 & 169.6 & 174.3 & 123.6 \\
\hline \#3724 & 0 & 69.9 & 69.9 & 167.2 & 113.6 & 129.7 & 155.7 & 230.6 & 184 & 230.6 & 115.6 \\
\hline \#6202 & 0 & 55.1 & 65.3 & 158 & 87.9 & 121.5 & 115.6 & 198.9 & 164.9 & 198.9 & 133.9 \\
\hline \multicolumn{12}{|c|}{ Group 4 - Previously infected } \\
\hline \#4818 & 0 & 24.1 & 40.7 & 23.1 & 0 & 25.1 & 11 & 81.1 & 77.8 & 89.6 & 48.3 \\
\hline \#4900 & 0 & 21.1 & 0 & 17.6 & 0 & 23.1 & 15 & 81.1 & 63.8 & 89.6 & 38.3 \\
\hline \#5146 & 93 & 73 & 76.2 & 81.1 & 35.9 & 63.8 & 51 & 96.7 & 63.8 & 109.8 & 60.8 \\
\hline \#5875 & 0 & 0 & 0 & 0 & 0 & 0 & 0 & 142.4 & 133.9 & 164.9 & 35.9 \\
\hline
\end{tabular}


of $81 \mathrm{~mm}^{2}$ for pony \#5146, the levels of which were steady over the entire protocol (Tab. I). Antibodies were also detected by SRH for ponies \#4818 and \#4900 even though they were not vaccinated, albeit at relatively low levels of between 0 and $41 \mathrm{~mm}^{2}$. Three of the four previously infected ponies seroconver-ted after challenge infection when tested against $\mathrm{A} / \mathrm{eq} / \mathrm{South}$ Africa/4/03 (the initial challenge strain). All four ponies seroconverted when tested against others antigens, but to much lower levels than the unvaccinated control ponies. The exception was Pony \#5875, which had no detectable antibody by SRH throughout the vaccination procedure, seroconverted to the highest level within the group to a mean antibody level of $142 \mathrm{~mm}^{2}$ against A/eq/ South Africa/4/03. Ponies \#4818 and \#4900 seroconverted but did not reach the same mean SRH antibody levels as pony $\# 5875$, both reaching a level $<90 \mathrm{~mm}^{2}$.

Mean SRH antibody levels obtained using the two Florida clade one viruses A/eq/South Africa/4/03 and A/eq/Sydney/2888-8/07 were not significantly different from each other $(p=0.23$; data not shown).

\subsection{Clinical responses to infection}

Four out of five control (Group 1) ponies developed pyrexia by day 2 post-infection with a mean temperature of $39.7 \pm 1.1{ }^{\circ} \mathrm{C}$ (Fig. 1). The pyrexia was biphasic in 3 out of 4 positive ponies as it dropped below the threshold for pyrexia on day 3 and 4 with a mean temperature of $38.2 \pm 0.25{ }^{\circ} \mathrm{C}$ and $38.1 \pm 0.2{ }^{\circ} \mathrm{C}$ for the group, respectively. On day 5 post-infection, a mean temperature of $39.7 \pm 0.8^{\circ} \mathrm{C}$ was recorded for two of the previously pyretic ponies, lasting only one day. One control pony (\#3791) became pyretic again on day 9 post-infection. Such elevation of body temperature late in the challenge phase was most likely associated with a secondary bacterial infection, which resolved quickly after treatment with antibiotics.

Group 2 ponies vaccinated with ProteqFlu ${ }^{\mathrm{TM}}$ did not develop pyrexia post-infection with a mean temperature of $38.0 \pm 0.2{ }^{\circ} \mathrm{C}$ for the group for the duration of the monitoring period (Fig. 1). One pony in Group 3 vaccinated with Equip ${ }^{\mathrm{TM}} \mathrm{F}$ was pyretic on days 3,4 and 5 with a mean tem- perature of $39.3 \pm 0.1{ }^{\circ} \mathrm{C}$ before returning to baseline levels. Another pony in Group 3 was pyretic at day 6 post-infection for one day only with a temperature of $39.6{ }^{\circ} \mathrm{C}$. None of the other ponies in Group 3 became pyretic over the monitoring period. One of the previously infected ponies in Group 4 became pyretic on day 3 post-infection which persisted for 2 days with a mean temperature of $39.9 \pm 0.5{ }^{\circ} \mathrm{C}$. None of the other previously infected ponies developed pyrexia over the monitoring period.

A clinical score was calculated per pony as referenced in Materials and Methods and is shown in Figure 2. The post-challenge clinical score was significantly reduced $(p=0.026)$ in vaccinated and previously infected ponies (Groups 2, 3 and 4) when compared to the unvaccinated ponies (Group 1). Significant differences were also observed in levels of coughing $(p=0.0135)$ and mucopurulent nasal discharge $(p=0.0139)$ when compared to control ponies.

\subsection{Virus shedding}

All control ponies (Group 1) shed live virus for a minimum of three to a maximum of 7 days post-challenge with a peak virus titre in eggs of $4.0 \log _{10} \mathrm{EID}_{50} / \mathrm{mL}$ recovered from one pony on day 3 (Figs. 3A and 3B). NP-ELISA positive data generally correlated well with isolation of live virus. Virus shedding appeared to be biphasic with lower NP-ELISA values collected on day 5 when compared to days 3, 4 and 6. Quantitative RT-PCR analysis mirrored the biphasic data observed in the NP-ELISA assay with peak copy numbers between $2.5 \times 10^{7} / \mathrm{mL}$ and $4 \times 10^{8} / \mathrm{mL}$ on day 3 and between $2.9 \times 10^{5} / \mathrm{mL}$ and $2.1 \times 10^{8} / \mathrm{mL}$ on day 6 post-infection. Viral RNA was detected on days 1 and 2, one day earlier than in the egg titration and 2 days earlier than the NP-ELISA for 4 of the 5 ponies. Pony \#1992 was virus positive in eggs on day 1 which corresponded to approximately 900 copies $/ \mathrm{mL}$ detected by quantitative RT-PCR. Furthermore, at days 8 to 10 the egg isolation and NP-ELISA assays were negative while viral RNA copies were still detected, albeit at lower levels than for earlier days post-infection. Up to approximately $2 \times 10^{4}$ copies $/ \mathrm{mL}$ were detected for 


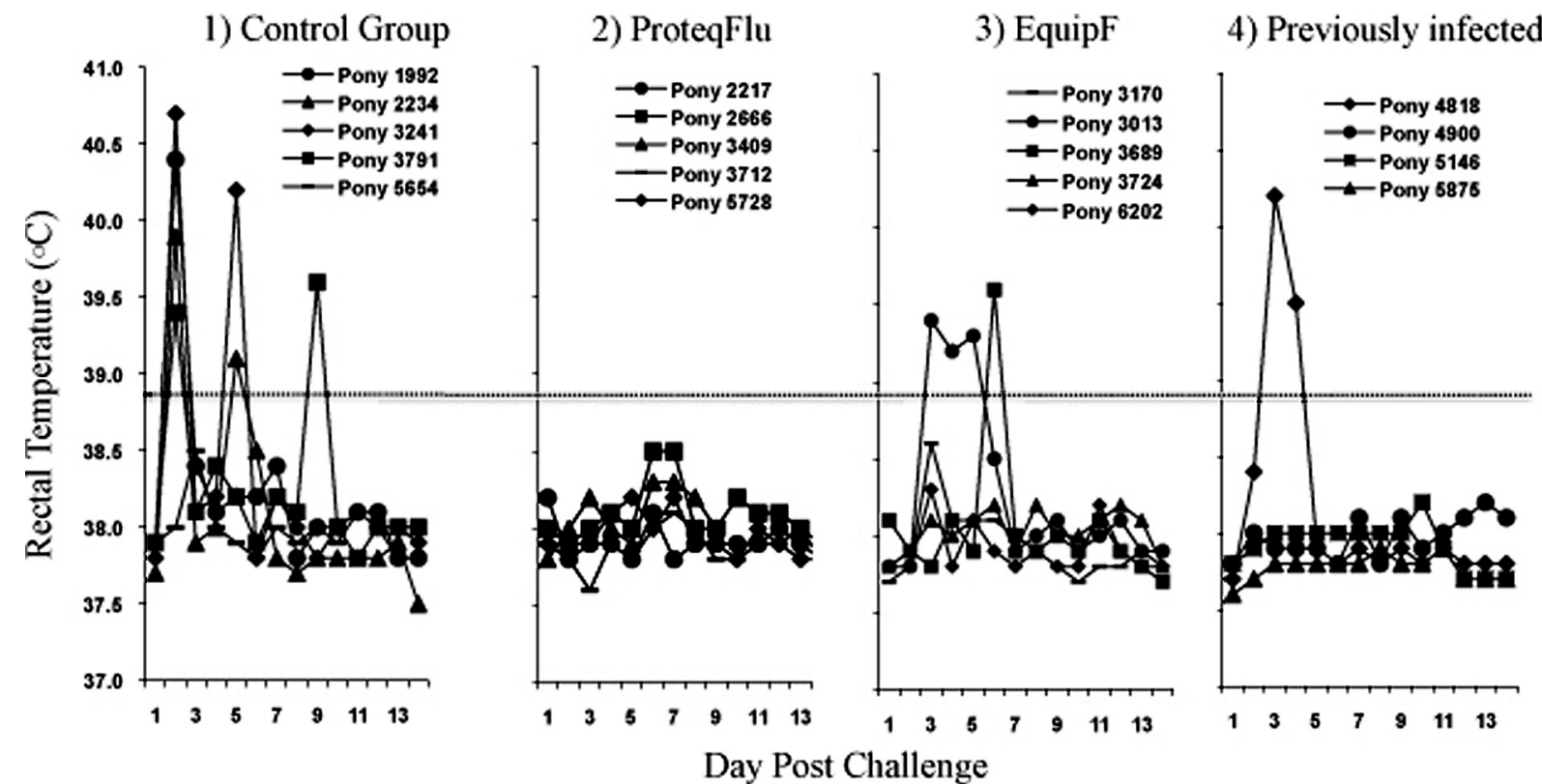

Figure 1. Rectal temperatures $\left({ }^{\circ} \mathrm{C}\right)$ measured daily of the four groups of ponies after challenge with A/eq/Sydney/2888-8/07. Individual ponies labeled as legend. 


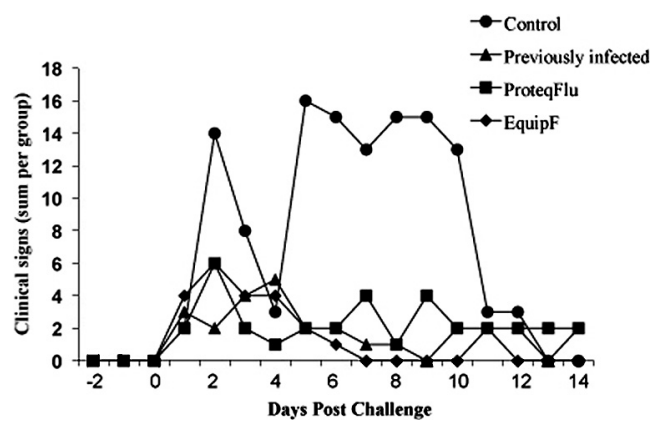

Figure 2. Total clinical scores for the four groups of ponies for 14 days post-challenge with A/eq/ Sydney/2888-8/07 as identified by the legend. Data includes rectal temperatures, nasal discharge, cough, inappetance, lethargy and dyspnoea.

ponies \#1992, \#2234, \#3791 and \#5654 and a minimum of $2.5 \times 10^{3}$ copies $/ \mathrm{mL}$ for pony \#3241 on day 10. Three of the four ponies previously infected with $\mathrm{A} / \mathrm{eq} / \mathrm{South}$ Africa/4/03 shed virus as determined by egg titration (Figs. 3C and 3D), for 1 to 3 days with a peak titre of $2.5 \log _{10} \mathrm{EID}_{50} / \mathrm{mL}$. The data from the NPELISA suggests that there were low levels of protein present when compared to the other groups within the study, although relatively high titres were measured in eggs in the case of pony numbers \#5146 and \#5875. On day 6 the NP-ELISA was positive for one pony but no virus was detected in eggs suggesting viral components were present but in an inactive form. The quantitative RT-PCR data showed virus shedding for all four ponies for up to approximately 7 days postinfection with peaks obtained for ponies \#5146 and $\# 5875$ on day 3 and 6 respectively. Interestingly, pony \#4900 that tested negative for virus shedding by NP-ELISA and eggs on day 2, 3 and 4 was positive by quantitative RT-PCR with a peak titre of $5.7 \times 10^{4}$ copies $/ \mathrm{mL}$.

Four of the five ponies in Group 2 (Proteq$\mathrm{Flu}^{\mathrm{TM}}$ ) shed live virus for 1 to 2 days post-infection with two of the ponies secreting a peak titre of $1.5 \log _{10} \mathrm{EID}_{50} / \mathrm{mL}$ on day 2 as determined by egg titration (Figs. $3 \mathrm{G}$ and $3 \mathrm{H}$ ). EIV was detected one day earlier in eggs for two ponies when compared to the NP-ELISA assay. Quantitative RT-PCR detected viral RNA from the five ponies for at least 7 days post-infection from days 1 or 2 to days 8 or 9 depending on the pony. The biphasic nature of virus shedding was evident for ponies \#2217, \#3409 and \#5728. Absolute copy number values were reduced in ponies \#3409, \#3712 and \#5728 when compared to controls. Furthermore, the NP-ELISA and quantitative RT-PCR detected virus in swab material that was unable to replicate in eggs on days 2 to 8 . Two of the five ponies in Group 3 (Equip $^{\mathrm{TM}} \mathrm{F}$ ) shed live virus over the monitoring period for 2 to 3 days, with a peak titre of 3.0 $\log _{10} \mathrm{EID}_{50} / \mathrm{mL}$ on day 4 post-infection for pony number \#3013. The NP-ELISA detected protein at the same time points at which virus replicated in the embryonated eggs, namely days 2 and 3 but not on day 4 or day 6 . The quantitative RT-PCR assay detected RNA copies for a minimum of 7 days post-infection for the five ponies (Figs. 3E and 3F). Ponies \#3013 and $\# 3170$ had peak copy numbers of $2.4 \times 10^{8}$ and $3.7 \times 10^{7}$ copies $/ \mathrm{mL}$ on day 2 respectively, which dropped rapidly until a second lower peak was recorded on day 6 post-infection with tires of $2.2 \times 10^{5}$ and $3.4 \times 10^{5}$ copies $/ \mathrm{mL}$. Furthermore, pony \#6202 which tested negative by egg titration and NP-ELISA throughout the challenge period had slowly increasing copy numbers from day 3 post-infection peaking at $3 \times 10^{7}$ copies/mL on day 6 .

There were statistically significant differences between the total amount of virus and the peak virus shed between the control group (Group 1) and the vaccinated groups $(p=$ $0.007)$ or the previously infected group $(p=$ 0.005 ) as measured by egg titration.

\section{DISCUSSION}

It is most likely that the 2007 Australian outbreak of EI was initiated by a subclinically infected imported horse that had responded poorly to vaccination ${ }^{3}$. The A/eq/Sydney/ 2888-8/07 strain classified as a member of the Florida sublineage clade 1 was very similar to viruses isolated from the 2007 EIV outbreak in Japan where numerous cases of vaccine breakdown were reported $^{3}[14,36]$. Furthermore, the Japanese vaccines used in 2007 
A

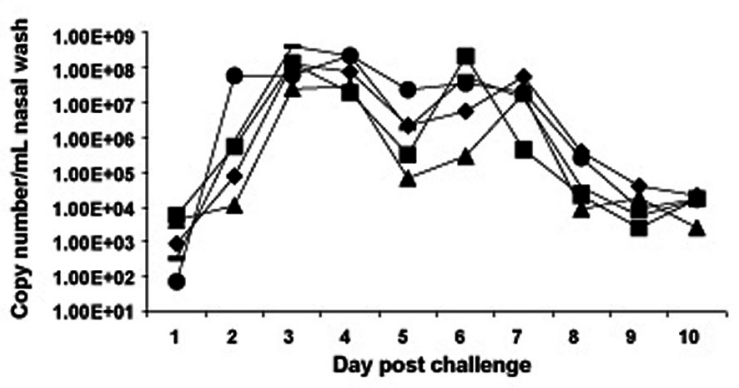

B
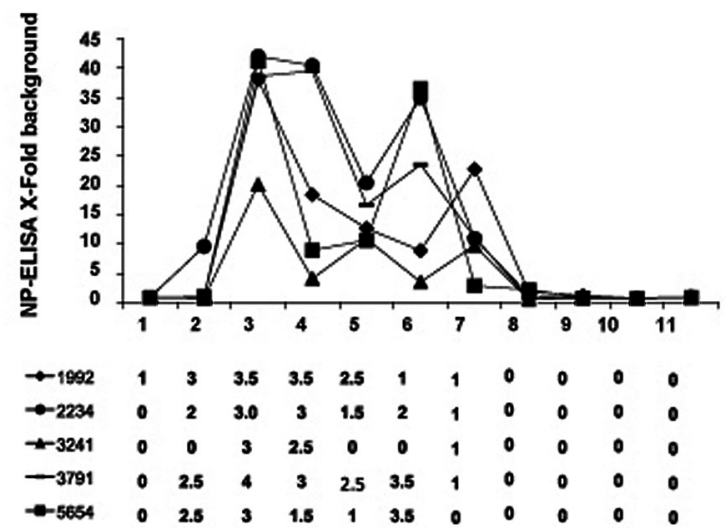

EIV titration

( $\log 10 \mathrm{EID}_{50} / \mathrm{mL}$ of swab extract)
C

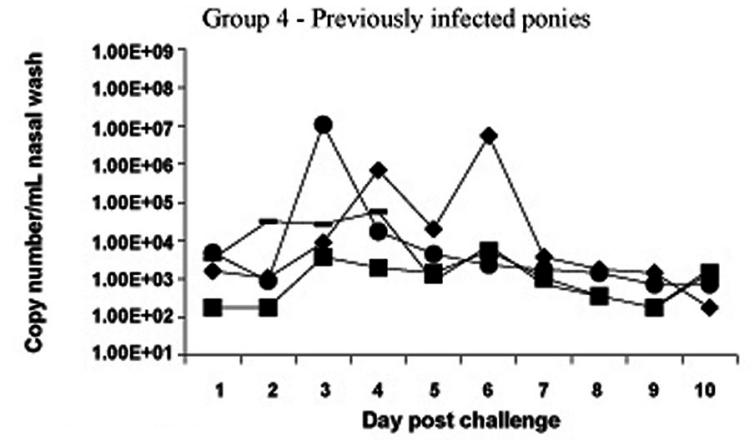

D

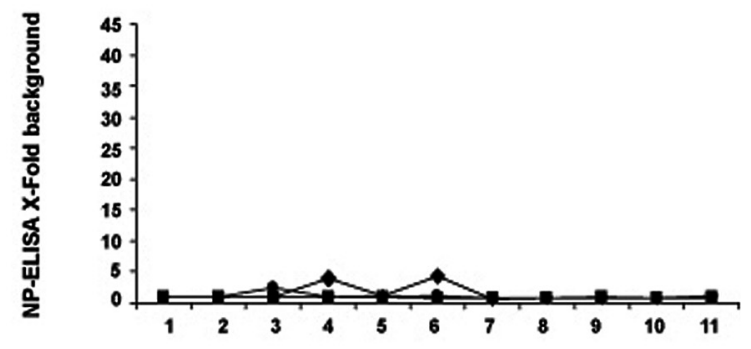

Figure 3. Quantification of virus shedding. Nasopharyngeal swabs were taken from each pony daily and virus was measured by quantitative PCR, NP-ELISA and egg titration. Individual ponies are identified by number and symbol as indicated within Group 1 (A, B), Group 2 (G, H), Group 3 $(\mathrm{E}, \mathrm{F})$ and Group $4(\mathrm{C}, \mathrm{D})$. 


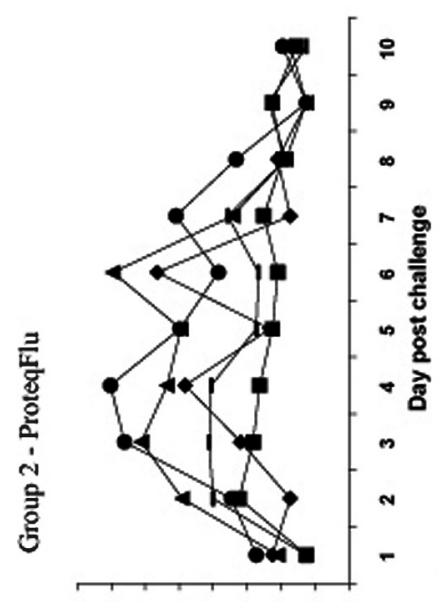

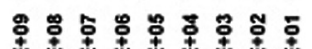

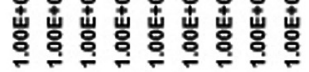
usem jeseu ךupequnu Kdoכ

U

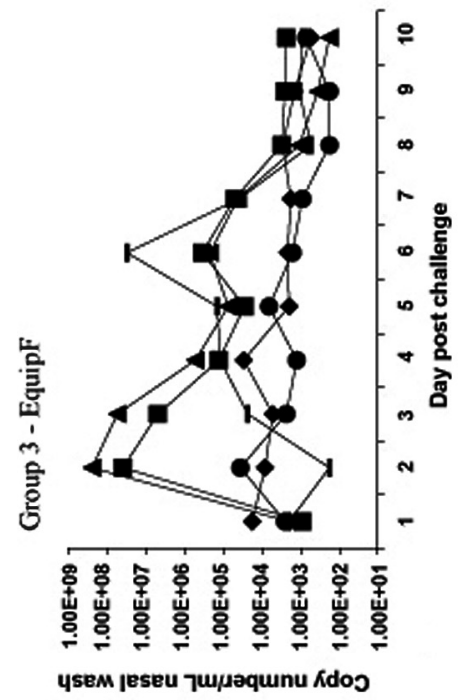

UI

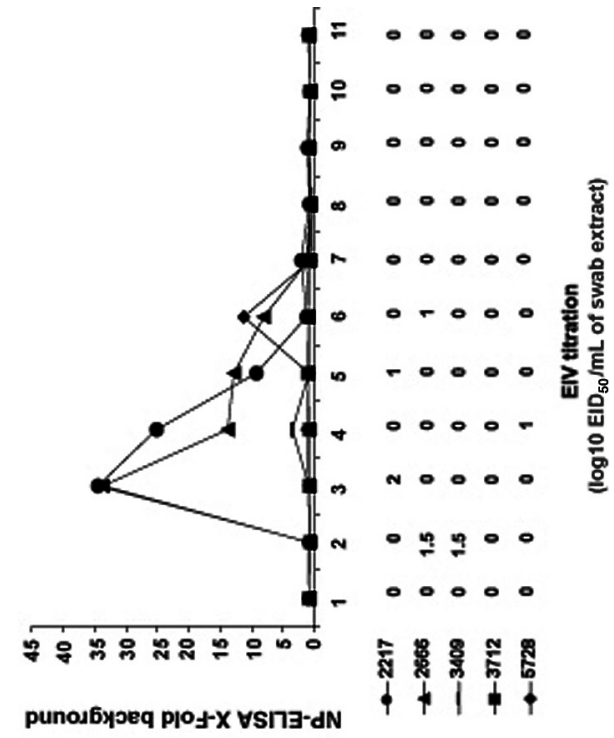

I

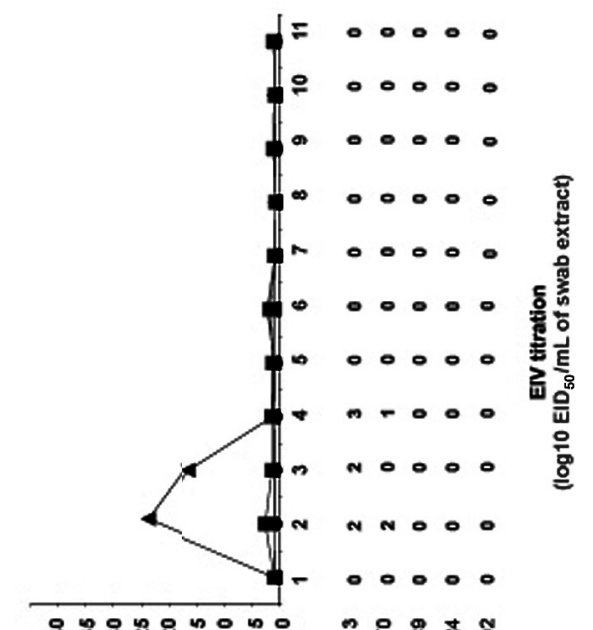

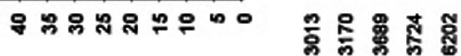

punou6yoeq plot-X $\forall S 173-d N$

نْ

(page number not for citation purpose) Page 11 of 15 
contained similar EIV strains to vaccines commercialised in the UK in 2003. Analysis of the EIV outbreak in Newmarket in 2003 demonstrated that protection induced by those vaccines was sub-optimal [1]. These data raised concerns about the efficacy of vaccines available in Europe against these more recent strains in the absence of any updated vaccines on the market [1]. This study was supported by the Horserace Betting Levy Board and designed to test the efficacy of two EIV vaccines commercially available in the UK at the time of the Japanese and Australian outbreaks, against infection with A/eq/Sydney/2888-8/07 strain. It offered a better understanding of the options available to the equine industry in order to control or limit the spread of a similar EIV strain if it came to circulate in Europe, in the absence of updated EI vaccines.

In a Welsh Mountain pony model both Equip $^{\mathrm{TM}} \mathrm{F}$ (Schering Plough) and ProteqFlu ${ }^{\mathrm{TM}}$ (Merial) were partially protective when challenged with A/eq/Sydney/2888-8/07, resulting in significantly reduced clinical signs of disease and virus shedding as measured in eggs and by quantitative RT-PCR when compared to unvaccinated ponies. This protection was achieved with 2 doses of vaccine administered 5 weeks apart as seen in previous efficacy studies with related EIV strains [10, 27, 29]. However, neither vaccine completely prevented virus shedding, despite the challenge taking place under optimised conditions with high antibody levels. This sub-optimal performance could be associated with the differences between vaccine and challenge strains. The vaccines used in this study contained A/eq/Kentucky/1/93 or $\mathrm{A} / \mathrm{eq} /$ Kentucky/98 HA, both American lineage viruses with 10 and 13 amino acid substitutions in HA1, respectively when compared to $\mathrm{A} / \mathrm{eq} / \mathrm{South}$ Africa/4/03 (the recommended vaccine strain) and 12 and 15 amino acid substitutions when compared with A/eq/Sydney/2888-8/07. Antibody levels as measured by SRH ranged from about 96 to $209 \mathrm{~mm}^{2}$ for Equip ${ }^{\mathrm{TM}} \mathrm{F}$ and about 115 to $186 \mathrm{~mm}^{2}$ for ProteqFlu ${ }^{\mathrm{TM}}$ at 2 weeks post V2 using A/eq/South Africa/4/03 as the antigen. The SRH values raised against A/eq/Sydney/ $2888-8 / 07$ in the assay ranged from 93 to $209 \mathrm{~mm}^{2}$ for Equip ${ }^{\mathrm{TM}} \mathrm{F}$ and 117 to $168 \mathrm{~mm}^{2}$ for ProteqFlu ${ }^{\mathrm{TM}}$. These SRH values are broadly similar for both antigens reflecting their close antigenic relationship (only 2 amino acids substitutions in HA1) and them both being members of the Florida sublineage clade $1^{3}$ [2]. Interestingly, the SRH values obtained when using A/eq/Newmarket/1/93 antigen on sera from $\mathrm{V} 2+2$ weeks (pre-challenge) were also broadly similar to those seen with $\mathrm{A} / \mathrm{eq} / \mathrm{Syd}$ ney/2888-8/07 and A/eq/South Africa/4/03 suggesting the antibody response was crossreactive in this assay. Pre-challenge SRH antibody levels against $\mathrm{A} / \mathrm{eq} / \mathrm{Newmarket} / 2 / 93$ for both vaccines were lower than those seen with those raised against the Florida sublineage viruses however after challenge all SRH antibody levels against $\mathrm{A} / \mathrm{eq} / \mathrm{Newmarket} / 2 / 93$ showed clear seroconversions to levels similar to the other antigens. The critical value for clinical protection was previously determined as $100 \mathrm{~mm}^{2}$ against the challenge virus, and levels of $150 \mathrm{~mm}^{2}$ and greater where shown to protect from virus shedding when using conventional inactivated vaccines [22]. These values were reduced to $90 \mathrm{~mm}^{2}$ and $>120 \mathrm{~mm}^{2}$ respectively, when using ISCOM vaccines with a lower heterologous challenge dose of $10^{6}$ $\mathrm{EID}_{50} / \mathrm{mL}$ of $\mathrm{A} / \mathrm{eq} /$ Newmarket $/ 79$ [23]. Based on these data, it would appear unlikely that one dose alone of either vaccine would induce antibody levels high enough in naïve ponies to protect against virus infection post V1 alone in a heterologous challenge, the most likely scenario in an outbreak situation. This suggests it may be necessary for horse populations to undergo a complete vaccination schedule to ensure efficacy in a naïve population. In this study ponies with mean SRH antibody levels of as high as 167 and $169 \mathrm{~mm}^{2}$ on the day of challenge after prime/boost immunisation with either vaccine did seroconvert after experimental infection with A/eq/Sydney/2888-8/07. This result indicated that neither vaccine provided sterile immunity against the Australian outbreak isolate, despite being tested under optimal conditions that are likely to provide a high level of protection.

In the field it is unlikely that all vaccinated animals would respond to the same level as seen here, and horses are likely to be at different 
points through their vaccination schedules when they encounter EIV. Antigenic drift in equine H3N8 viruses further reduces the efficacy of vaccines and can lead to these viruses not being recognised by pre-existing antibodies generated by infection or vaccination with an antigenically distant strain. Previous studies with non-adjuvanted inactivated virus vaccines have been able to identify differences between the level of protection provided against homologous and heterologous challenge $[6,7,37]$. For this reason the OIE has recommended for several years that EIV vaccines be updated to include a Eurasian lineage strain (e.g. A/eq/Newmarket/2/93) and a Florida sublineage clade 1 virus (e.g. A/eq/ South Africa $/ 4 / 03)^{1}$. At the time of this experiment, no vaccine was available in the UK that met these requirements. The authors fully support the OIE recommendation and note that vaccines containing these updated strains are now available. As of 2009, the OIE has dropped the recommendation for a Eurasian lineage strain to be included in EIV vaccines as they are no longer circulating in the field ${ }^{4}$. In the Newmarket EIV outbreak in 2003 there were numerous reports of vaccine breakdown although the vaccines themselves were inducing high antibody levels that would normally considered to be protective [25]. Vaccines employed in Newmarket in 2003 contained A/eq/Newmarket/1/93 with aluminium hydroxide adjuvant. Later work has suggested that protective immunity conveyed by these vaccines was sub-optimal compared to other vaccines preparations [1] but whether this was the case in Japan or not has not been determined.

The vaccines tested in this report have been shown to generate an EIV-specific IFN $\gamma$ response, which is a marker of cell-mediated immunity in the horse [27-29]. In man, it is thought that cellular immune mechanisms play an important role in clearance of virus from the respiratory tract [18]. Infection with EIV has been shown to induce long-term immunity

\footnotetext{
${ }^{4}$ Expert surveillance panel on equine influenza vaccine composition - Conclusions and recommandations, 2009, pp. 42-43. http://www.oie.int/ eng/publicat/BULLETIN\%20PDF/Bull\%202009-2ENG.pdf.
}

independent of circulating antibodies against HA [11]. Of the previously infected ponies studied in this report, 3 of the 4 had detectable SRH antibody levels 18 months post-infection with only one above $75 \mathrm{~mm}^{2}$. Antibody levels after natural EI infection usually wane rapidly. The antibody response was monitored regularly in this group of ponies after the initial experimental infection with $\mathrm{A} / \mathrm{eq} /$ South Africa/4/03. SRH antibodies were still detectable 12 months after the initial EIV infection (between 22 to $75 \mathrm{~mm}^{2}$; data not shown), which was consistent with the data presented in this report. Kinetics of the antibody response shown a slow decrease instead challenge infection, without evidence of anamnestic response (data not shown). No evidence of field EI infection (clinical signs or serology) were recorded on the premise where these four ponies and other EIV naïve ponies were kept during the 18 months separating the 2 experimental infection with EIV (A/eq/South Africa/4/03 and A/eq/Sydney/2888-8/07, respectively). This pony did not seroconvert after challenge infection but it did shed virus on days 3 and 4 , suggesting that it was productively infected with virus. During the vaccination phase, two of the other previously infected ponies (Group 4) developed low but detectable levels of antibody, specific for EIV despite not being vaccinated.

After challenge infection with A/eq/Sydney/ $2888-8 / 07$, the level of SRH antibody was significantly lower than in other groups $(p<0.01)$, with only 3 out of 4 ponies seroconverting. All previously infected ponies in Group 4 showed significantly reduced clinical signs of disease and virus shedding when compared with control ponies. This result confirms the previous observations that horses that have previously been in contact with EIV develop an EIVspecific memory response that is rapidly stimulated and able to provide significant protection, despite absent or low levels of antibody at the time of infection. Both $\mathrm{B}$ and $\mathrm{T}$ cell memory responses are expected to be quickly stimulated by re-infection with EIV, their respective importance and role in protection is still unclear.

Three different methods were used for quantifying the amount of virus shed and collected by nasopharyngeal swabbing. To date most 
vaccine efficacy and challenge studies have been conducted using egg titration as the method of choice, with the obvious advantage of detecting only infectious virus [8, 10, 19, 29]. However, this study has shown that quantitative RT-PCR was more sensitive than both virus isolation in eggs and NP-ELISA, detecting viral RNA earlier and for longer than the other methods even in ponies showing no clinical signs of EIV infection. The quantitative RT-PCR protocol was able to detect less than 10 RNA copies when using in vitro transcribed RNA template. A limitation of the egg titration protocol used was that it relies on just one egg passage at 4 different virus dilutions from neat to $10^{-4}$ and detection by HA assay that itself is not very sensitive. Virus isolation from nasopharyngeal swabs taken from horses in the field can take up to 5 egg passages before an HA positive egg is obtained [2]. This may account for some of the negative results obtained in eggs when compared to NP-ELISA or quantitative RT-PCR. Another alternative explanation for this result may be that the virus particles present in the nasal secretions may be rendered non-infections by the binding of secreted antibody, particularly in vaccinated ponies with high antibody levels.

In conclusion the results obtained in this study suggested that both vaccines should provide a reasonable level of clinical protection for UK horses if a strain of EIV similar to that occurring in Australia or Japan were to become established in this country. Since they reduced the level and duration of virus shedding, the current vaccines should also help reduce the spread of the disease, particularly if used in the face of an outbreak where high herd immunity can be induced at a local level in the short term before updated vaccines became available. We fully endorse the recommendations of the OIE Expert Surveillance Panel who continue to recommend that current vaccines be updated to a more recent virus (A/eq/Ohio/03 or A/eq/South Africa/ $4 / 03)^{4}$. We strongly believe that inclusion of such a strain in vaccines would further improve prevention and control of EIV outbreaks.

Acknowledgements. We would like to thank the yard staff at the AHT for their care of the ponies and V. Hawkes (Proligo) for help in primer and probe design.
The work was funded by the Horse Race Betting Levy Board (HBLB). N.S. Lewis was supported by the Cambridge Infectious Diseases Consortium as part of the DEFRA Veterinary Training and Research Initiative.

\section{REFERENCES}

[1] Barquero N., Daly J.M., Newton J.R., Risk factors for influenza infection in vaccinated racehorses: lessons from an outbreak in Newmarket, UK in 2003, Vaccine (2007) 25:7520-7529.

[2] Bryant N.A., Rash A.S., Russell C.A., Ross J., Cooke A., Bowman S., et al., Antigenic and genetic variations in European and North American equine influenza virus strains (H3N8) isolated from 2006 to 2007, Vet. Microbiol. (2009) 138:41-52.

[3] Cook R.F., Sinclair R., Mumford J.A., Detection of influenza nucleoprotein antigen in nasal secretions from horses infected with A/equine influenza (H3N8) viruses, J. Virol. Methods (1988) 20:1-12.

[4] Cullinane A., Weld J., Osborne M., Nelly M., McBride C., Walsh C., Field studies on equine influenza vaccination regimes in thoroughbred foals and yearlings, Vet. J. (2001) 161:174-185.

[5] Daly J.M., Lai A.C., Binns M.M., Chambers T.M., Barrandeguy M., Mumford J.A., Antigenic and genetic evolution of equine H3N8 influenza A viruses, J. Gen Virol. (1996) 77:661-671.

[6] Daly J.M., Yates R.J., Browse G., Swann Z., Newton J.R., Jessett D., et al., Comparison of hamster and pony challenge models for evaluation of effect of antigenic drift on cross protection afforded by equine influenza vaccines, Equine Vet. J. (2003) 35:458-462.

[7] Daly J.M., Yates P.J., Newton J.R., Park A., Henley W., Wood J.L., et al., Evidence supporting the inclusion of strains from each of the two co-circulating lineages of H3N8 equine influenza virus in vaccines, Vaccine (2004) 22:4101-4109.

[8] Daly J.M., Sindle T., Tearle J., Barquero N., Newton J.R., Corning S., Equine influenza vaccine containing older H3N8 strains offers protection against A/eq/South Africa/4/03 (H3N8) strain in a short-term vaccine efficacy study, Equine Vet. J. (2007) 39:446-450.

[9] East I.J., The role of land use patterns in limiting the spread of equine influenza in Queensland during the 2007 epidemic, Transbound. Emerg. Dis. (2009) 56:292-302.

[10] Edlund Toulemonde C., Daly J., Sindle T., Guigal P.M., Audonnet J.C., Minke J.M., Efficacy of a recombinant equine influenza vaccine against challenge with an American lineage H3N8 influenza virus responsible for the 2003 outbreak in the United Kingdom, Vet. Rec. (2005) 156:367-371.

[11] Hannant D., Mumford J.A., Jessett D.M., Duration of circulating antibody and immunity following infection with equine influenza virus, Vet. Rec. (1988) 122:125-128. 
[12] Heldens J.G., Kersten A.J., Weststrate M.W., van den Hoven R., Duration of immunity induced by an adjuvanted and inactivated equine influenza, tetanus and equine herpesvirus 1 and 4 combination vaccine, Vet. Q. (2001) 23:210-217.

[13] Heldens J.G., Pouwels H.G., van Loon A.A., Efficacy and duration of immunity of a combined equine influenza and equine herpesvirus vaccine against challenge with an American-like equine influenza virus (A/equi-2/Kentucky/95), Vet. J. (2004) 167:150-157.

[14] Ito M., Nagai M., Hayakawa Y., Komae H., Murakami N., Yotsuya S., et al., Genetic analyses of an $\mathrm{H} 3 \mathrm{~N} 8$ influenza virus isolate, causative atrain of the outbreak of equine influenza at the Kanazawa racecourse in Japan in 2007, J. Vet. Med. Sci. (2008) 70:899-906.

[15] Kucera C.J., Beckenhauer W.H., Studies on the antigenicity of an inactivated, aluminum hydroxide adjuvant equine influenza vaccine, Can. J. Comp. Med. (1977) 41:326-331.

[16] Lai A.C., Chambers T.M., Holland R.E. Jr, Morley P.S., Haines D.M., Townsend H.G., Barrandeguy M., Diverged evolution of recent equine-2 influenza (H3N8) viruses in the Western Hemisphere, Arch. Virol. (2001) 146:1063-1074.

[17] Martella V., Elia G., Decaro N., Di Trani L., Lorusso E., Campolo M., et al., An outbreak of equine influenza virus in vaccinated horses in Italy is due to an $\mathrm{H} 3 \mathrm{~N} 8$ strain closely related to recent North American representatives of the Florida sub-lineage, Vet. Microbiol. (2007) 121:56-63.

[18] McMichael A.J., Gotch F.M., Noble G.R., Beare P.A., Cytotoxic T-cell immunity to influenza, N. Engl. J. Med. (1983) 309:13-17.

[19] Minke J.M., Toulemonde C.E., Coupier H., Guigal P.M., Dinic S., Sindle T., et al., Efficacy of a canarypoxvectored recombinant vaccine expressing the hemagglutinin gene of equine influenza $\mathrm{H} 3 \mathrm{~N} 8$ virus in the protection of ponies from viral challenge, Am. J. Vet. Res. (2007) 68:213-219.

[20] Mumford J., Wood J.M., Scott A.M., Folkers C., Schild G.C., Studies with inactivated equine influenza vaccine. 2 . Protection against experimental infection with influenza virus A/equine/Newmarket/79 (H3N8), J. Hyg. (Lond.) (1983) 90:385-395.

[21] Mumford J.A., Wood J.M., Folkers C., Schild G.C., Protection against experimental infection with influenza virus A/equine/Miami/63 (H3N8) provided by inactivated whole virus vaccines containing homologous virus, Epidemiol. Infect. (1988) 100:501-510.

[22] Mumford J.A., Wood J., Establishing an acceptability threshold for equine influenza vaccines, Dev. Biol. Stand. (1992) 79:137-146.

[23] Mumford J.A., Jessett D.M., Rollinson E.A., Hannant D., Draper M.E., Duration of protective efficacy of equine influenza immunostimulating complex/tetanus vaccines, Vet. Rec. (1994) 134:158-162.
[24] Newton J.R., Wood J.L., Dunn K.A., DeBrauwere M.N., Chanter N., Naturally occurring persistent and asymptomatic infection of the guttural pouches of horses with Streptococcus equi, Vet. Rec. (1997) 140:84-90.

[25] Newton J.R., Daly J.M., Spencer L., Mumford J.A., Description of the outbreak of equine influenza (H3N8) in the United Kingdom in 2003, during which recently vaccinated horses in Newmarket developed respiratory disease, Vet. Rec. (2006) 158:185-192.

[26] Paillot R., Hannant D., Kydd J.H., Daly J.M., Vaccination against equine influenza: quid novi?, Vaccine (2006) 24:4047-4061.

[27] Paillot R., Kydd J.H., Sindle T., Hannant D., Edlund Toulemonde C., Audonnet J.C., et al., Antibody and IFNgamma responses induced by a recombinant canarypox vaccine and challenge infection with equine influenza virus, Vet. Immunol. Immunopathol. (2006) 112:225-233.

[28] Paillot R., Kydd J.H., MacRae S., Minke J.M., Hannant D., Daly J.M., New assays to measure equine influenza virus-specific Type 1 immunity in horses, Vaccine (2007) 25:7385-7398.

[29] Paillot R., Grimmett H., Elton D., Daly J.M., Protection, systemic IFNgamma, and antibody responses induced by an ISCOM-based vaccine against a recent equine influenza virus in its natural host, Vet. Res. (2008) $39: 21$.

[30] Powell D.G., Burrows R., Spooner P., Mumford J., Thomson G., Field observations on influenza vaccination among horses in Britain, 1971-1976, Dev. Biol. Stand. (1977) 39:347-352.

[31] Sovinova O., Tumova B., Pouska F., Nemec J., Isolation of a virus causing respiratory disease in horses, Acta Virol. (1958) 2:52-61.

[32] Waddell G.H., Teigland M.B., Sigel M.M., A new influenza virus associated with equine respiratory disease, J. Am. Vet. Med. Assoc. (1963) 143:587-590.

[33] Webster R.G., Are equine 1 influenza viruses still present in horses?, Equine Vet. J. (1993) 25:537-538.

[34] Wood J.L., Mumford J.A., Mair T.S., Slater J., Boosting in equine influenza vaccination schedules: timing and time for a re-evaluation of requirements of national and international authorities, Vet. J. (2007) $174: 449-450$

[35] Wood J.M., Schild G.C., Folkers C., Mumford J., Newman R.W., The standardization of inactivated equine influenza vaccines by single-radial immunodiffusion, $\mathrm{J}$. Biol. Stand. (1983) 11:133-136.

[36] Yamanaka T., Niwa H., Tsujimura K., Kondo T., Matsumura T., Epidemic of equine influenza among vaccinated racehorses in Japan in 2007, J. Vet. Med. Sci. (2008) 70:623-625.

[37] Yates P., Mumford J.A., Equine influenza vaccine efficacy: the significance of antigenic variation, Vet. Microbiol. (2000) 74:173-177. 